\title{
Prolonged or serious conflicts at work and incident dementia: a 23- year follow-up of the Copenhagen City Heart Study
}

\author{
Kazi Ishtiak-Ahmed ${ }^{1}$ ( ) Åse Marie Hansen ${ }^{1,2} \cdot$ Erik Lykke Mortensen $^{1,3} \cdot$ Anne Helene Garde $^{1,2} \cdot$ Ane Nørgaard $^{5}$. \\ Finn Gyntelberg ${ }^{2} \cdot$ Naja Hulvej Rod ${ }^{1} \cdot$ Sabrina Islamoska ${ }^{1} \cdot$ Rikke Lund ${ }^{1,3} \cdot$ Thien Kieu Thi Phung $^{3} \cdot$ Eva Prescott $^{4}$. \\ Gunhild Waldemar $^{5} \cdot$ Kirsten Nabe-Nielsen $^{1}$
}

Received: 15 March 2018 / Accepted: 21 October 2018 / Published online: 28 October 2018

(c) The Author(s) 2018

\begin{abstract}
Purpose Only a few studies have investigated the impact of negative aspects of social relations on cognitive function, and they have shown mixed results. Conflicts at work are part of the negative aspects of social relations, but the impact of experiencing conflicts at work has not yet been investigated as a risk factor for dementia. Therefore, we investigated whether experiencing prolonged or serious conflicts with a supervisor or colleagues at work was associated with incident dementia in old age. Methods We analyzed data of 6,436 men and women from the third survey of the Copenhagen City Heart Study. At baseline in 1991-1994, the participants reported whether they had ever had a prolonged or serious conflict at work. The participants were followed until 2014. We used Poisson regression to estimate incidence rate ratios (IRR) and their 95\% confidence intervals (CI).

Results After adjusting for potential confounders, the IRR for dementia was 1.53 (95\% CI 0.77-3.03) among participants who had reported having prolonged or serious conflicts both with a supervisor and colleagues compared with participants who had never had such conflicts. In separate analyses stratified by sex, the IRRs were 2.14 ( $95 \% \mathrm{Cl} 0.97-4.71)$ for men and 0.98 (95\% $\mathrm{Cl} 0.29-3.32)$ for women.

Conclusions Our findings did not support an overall association between experiencing prolonged or serious conflicts at work and incident dementia. However, because of the large differences in the point estimates for men and women, future research could aim at investigating potential sex differences regarding the association between conflicts at work and dementia.
\end{abstract}

Keywords Social relations · Negative aspects of social relations $\cdot$ Psychosocial work factors $\cdot$ Alzheimer's $\cdot$ Midlife risk factors · Cohort study

\begin{tabular}{|c|c|}
\hline Abbr & lations \\
\hline IRR & Incidence rate ratios \\
\hline
\end{tabular}

Kazi Ishtiak-Ahmed

kaah@sund.ku.dk

1 Department of Public Health, University of Copenhagen, Øster Farimagsgade 5, 1014 Copenhagen, Denmark

2 The National Research Centre for the Working Environment, Lersø Parkallé 105, 2100 Copenhagen, Denmark

3 Center for Healthy Aging, University of Copenhagen, Blegdamsvej 3B, 2200 Copenhagen, Denmark

4 Department of Cardiology, Bispebjerg University Hospital, Bispebjerg Bakke 23, 2400 Copenhagen, Denmark

5 Department of Neurology, Danish Dementia Research Centre, Rigshospitalet, University of Copenhagen Section 6911, Blegdamsvej 9, 2100 Copenhagen, Denmark
A $\beta \quad \beta$-Amyloid peptide

CCHS The Copenhagen City Heart Study

PPV Positive predictive value

SD Standard deviation

ICD International classification of diseases

CVD Cardiovascular disease

BMI Body mass index

\section{Introduction}

A growing body of research has shown a positive effect of social relations in private life on cognitive health (Kuiper et al. 2016), while lack of social relations (low social participation, less frequent social contact and loneliness) has been associated with a higher risk of dementia (Kuiper et al. 2015). Social relations may be a source of support, but may 
also be a source of relational strain including conflicts and excessive demands (Due et al. 1999). A few studies have investigated the effect of negative aspects of social relations, i.e., conflicts, social strain or negative social interactions causing worries, problems, and stress on cognitive function (Hughes et al. 2008; Liao et al. 2014; Seeman et al. 2001, 2011; Xu et al. 2016). These studies reported mixed results and focused primarily on older populations. None of these studies used clinically diagnosed dementia as outcome. In a study on emotional effects of daily stressors, interpersonal conflicts were identified as the most important stressors, and these conflicts had the strongest adverse effect on a person's mood (Bolger et al. 1989). Likewise, conflicts at work have also been considered to be severe stressors (Frone 2000; Spector and Bruk-Lee 2008). Thus, experiencing prolonged or serious conflicts at work could be considered as severe stressors.

A potential harmful effect of experiencing prolonged or serious conflicts at work on the development of cognitive impairment or dementia might be due to activation of the physiological stress response (Sherman et al. 2016). Stress increases the release of cortisol, which is known to cause hippocampal atrophy and production/deposition of $\beta$-amyloid peptide $(\mathrm{A} \beta)$ in the brain (Dong and Csernansky 2009). Deposition of $A \beta$ in the brain is a pathological hallmark of Alzheimer's disease, which is the most common type of dementia (Dong and Csernansky 2009). A prospective study showed a link between reporting stress in midlife and brain atrophy and white matter lesions in old age (Johansson et al. 2012), which have been suggested to be a mechanism linking midlife psychological stress and risk of dementia in old age (Johansson et al. 2010). Conflicts usually seem to have a temporary effect on health, but if conflicts are poorly managed, the effect could be long term (Carsten et al. 2004). Long-term conflicts are known to be a source of chronic stress (Cohen 2004). Chronic stress is often linked to cardiovascular risk factors and cardiovascular disease (CVD) (Steptoe and Kivimaki 2012). Midlife cardiovascular risk factors, such as blood pressure and cholesterol, have shown to be associated with risk of dementia in later life (Gottesman et al. 2017; Kivipelto et al. 2001). Moreover, being a severe social stressor, experiencing prolonged or serious conflicts may negatively influence individuals' health behaviors (Cohen 2004; Umberson et al. 2010), which may eventually influence cognitive health. Furthermore, Alzheimer's disease, the major cause of dementia, has a long pre-clinical phase that can last from a few years to a decade. This means that the underlying brain pathology occurs many years before the disease manifests itself, perhaps already in midlife (40-65 years) (Livingston et al. 2017). Taken altogether, it seems plausible that experiencing prolonged or serious conflicts in midlife may be associated with the risk of dementia later in life.
Experiencing conflicts at work is common. According to a national report in Denmark, one out of five people at the Danish workplaces experiences conflicts at work (The National Research Center for the Working Environment 2016). Interpersonal conflicts at work are associated with poor self-reported general health (De Raeve et al. 2009), poor sleep quality (Fortunato and Harsh 2006), psychiatric morbidity (Romanov et al. 1996), depression (Hagerty and Williams 1999; Meier et al. 2014), and work disability (Appelberg et al. 1996). Despite the high prevalence of conflicts at work (Malgorzata et al. 2009; The National Research Center for the Working Environment 2016) and despite the fact that it is considered a severe social stressor associated with mental disorders, the effect of conflicts at work on the risk of dementia has not yet been investigated. In the current study, we aimed to investigate whether experiencing prolonged or serious conflicts with a supervisor or colleagues at work was associated with incident dementia in old age.

\section{Methods}

\section{Study population}

The study population was drawn from the third survey of the Copenhagen City Heart Study (CCHS) (Aguib and Al Suwaidi 2015). In the first survey of CCHS in 1975, a sample of 19,698 men and women (aged 20+ years) were randomly selected from 90,000 inhabitants of a defined area of central Copenhagen. In the second survey in 1981-1983, the original sample was supplemented with 500 participants. In the third survey in 1991-1994, 3000 participants were added to the previous sample. The third survey formed the baseline in the current study. Out of the 16,563 invited, 10,135 persons agreed to participate. Participants with missing information about conflicts at work ( $n=1061)$ were excluded. The excluded participants were older (mean age 70.5 years) than the included participants (mean age 61.2 years), and the majority of them were on an old-age pension.

We started follow-up time when the participants turned 60 years. However, to reduce reverse causality, follow-up time did not start within the 5 years after the baseline assessment in 1991-1994. Applying these two criteria, we were left with 6,436 participants (3666 women) for the analyses, and their mean age was 61.2 years (standard deviation, $\mathrm{SD}=11)$ at baseline. The included participants were followed up until the date of a dementia diagnosis, emigration, death, or to the end of 2014, whichever came first. The flowchart of the selection of the study population is presented in Fig. 1. 
Fig. 1 Selection of the study participants for analyses

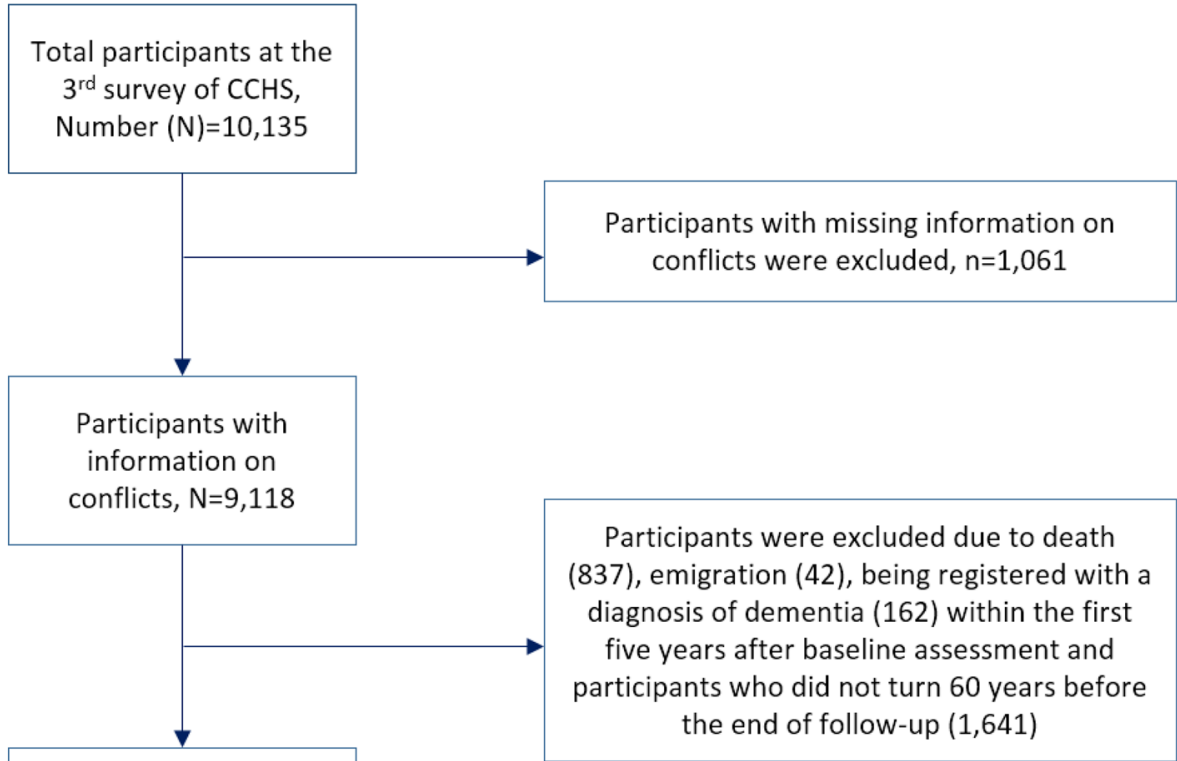

Included in the

analyses, $\mathrm{N}=6,436$

CCHS: The Copenhagen City Heart Study

\section{Prolonged or serious conflicts at work}

Prolonged or serious conflicts at work were assessed by two questions: (i) "Have you ever had a prolonged or serious conflict with your supervisor?", and (ii) "Have you ever had a prolonged or serious conflict with your colleagues?" Response options for both questions were "yes/no".

We analyzed these questions by categorizing the participants into four response groups: participants who (a) never had a prolonged or serious conflict neither with a colleague nor with a supervisor, (b) had a prolonged or serious conflict only with a supervisor, (c) had a prolonged or serious conflict only with a colleague, and (d) had prolonged or serious conflicts with both a supervisor and a colleague.

To experience conflicts with a supervisor and colleagues, participants must have had a job at some point before the baseline. This was verified by linkage to a Danish register with information about employment status (The Employment Classification Module). All of the included participants had been employed at some point between 1976 (start of the register) and the year of the baseline survey.

\section{Dementia diagnoses}

We extracted information on dementia diagnoses from the Danish national registers. List of sources of registers, applied diagnostic codes and the numbers of dementia cases identified are presented in Table 1 . Because of the low validity of the dementia subtypes in the registers, we did not differentiate between dementia subtypes in our data analyses (Phung et al. 2007).

\section{Covariates}

From the national registers in Denmark, we obtained information about the participants' age, sex, educational attainment (0-9 years/11-12 years/>12 years of formal schooling), co-morbidities before baseline including register-based diagnoses of diabetes and CVD (i.e., any ischemic heart disease and cerebrovascular disease, yes/no), and psychiatric disorders (record of hospitalization in a psychiatric department/hospital before baseline).

In the questionnaire, the participants were asked about the frequency of contact with parents, children, other family members, meeting colleagues outside of working hours, neighbors, childhood and youth friends, other friends, acquaintances, and house assistants. They were asked about their satisfaction with these contacts (response options: very much/more or less, or not at all) and whether they could talk about something personal with any of these contacts (i.e., whether they had a confidant). We used the latter two questions as two separate variables in our analyses as a measure of social relations in private life.

Information about lifestyle/CVD-risk factors was obtained from questionnaires: (i) smoking (current smoker/ past smoker/never smoker), (ii) physical activity in leisure time (almost sedentary life/light physical activity/moderate physical activity or vigorous physical activity), (iii) the 
Table 1 Number of dementia cases identified in the Danish national registers

\begin{tabular}{|c|c|c|c|}
\hline Dementia sub-types & ICD codes & Number of cases & List of source registers \\
\hline Alzheimer's disease & ICD-8: 290.09; ICD-10: F00.0-9, G30.0-9 & 214 & The Danish Psychiatric Central Research \\
\hline Vascular dementia & ICD-8:293.09-19; ICD-10:F01.0-9 & 68 & Register (Munk-Jorgensen and \\
\hline $\begin{array}{l}\text { Frontotemporal dementia/ } \\
\text { dementia with Lewy bodies }\end{array}$ & $\begin{array}{l}\text { ICD-8: 290.11; ICD-10: F02.0/ ICD-10: } \\
\text { G31.8 }\end{array}$ & $23^{\mathrm{b}}$ & $\begin{array}{l}\text { Mortensen 1997) } \\
\text { The Danish National Patient Register } \\
\text { (Andersen et al. 1999) and }\end{array}$ \\
\hline Dementia without specification & ICD-8: 290.09; ICD-10:F03.9, G31.9 & 440 & $\begin{array}{l}\text { The Danish Register of Causes of Death } \\
\text { (Helweg-Larsen 2011) }\end{array}$ \\
\hline Total number of dementia cases & & $745^{\mathrm{a}}$ & \\
\hline
\end{tabular}

ICD International Classification of Diseases

${ }^{a}$ There were nine cases that had double sub-types

${ }^{\mathrm{b}}$ The vast majority were dementia with Lewy bodies (Statistics Denmark does not provide data with a frequency of $\leq 3$, which is the case of frontotemporal dementia; therefore, we obtained a combined figure for both subtypes)

average unit of alcohol consumption per week (beer, glass of wine, spirits), and (iv) use of sleeping pills.

From the clinical examination, we obtained information on the participants' body mass index $(\mathrm{BMI})=($ weight in $\mathrm{kg}) /(\text { height in meter })^{2}$, and systolic blood pressure $(\mathrm{mmHg})$. Age, average alcohol consumption per week, BMI, and systolic blood pressure were analyzed as continuous variables.

\section{Statistical analyses}

To examine the association between prolonged or serious conflicts at work and incident dementia in old age, we used Poisson regression analyses and estimated incidence rate ratios (IRR) and their 95\% confidence intervals (95\% CI).

In the multivariable analyses, we adjusted for covariates that are likely to be potential confounders of the association between conflicts at work and dementia. In model 1, we adjusted for current age, sex, time since baseline assessment, and calendar year. In model 2, we further included participants' educational attainment, psychiatric disorders, and private life social relations (Livingston et al. 2017; Stein et al. 2008). In model 3, we also included lifestyle/CVD-risk factors (smoking, physical activity in leisure time, alcohol consumption, BMI, systolic blood pressure and use of sleeping pills), and comorbidities (diabetes, CVD).

The group of covariates included in model 3 could be confounders as well and mediators of the investigated relationship between conflicts at work and dementia (Rod et al. 2009; Stein et al. 2008; Umberson et al. 2010). From the available information in our data, we are not certain about the temporal relationship between experiencing prolonged or serious conflicts at work and any changes in lifestyle/ CVD-risk factors. Therefore, we considered model 2 as our main model.

A total of 204 (3.2\%) participants had missing information on at least one variable (satisfaction with private life social relations, $n=70$; smoking, $n=1$; physical activity during leisure time, $n=18$; alcohol, $n=45$; BMI, $n=54$; blood pressure, $n=43$, and use of sleeping pills, $n=26$ ). Participants with missing information were excluded analysis-by-analysis. A loss to follow-up due to emigration was minimal $(0.6 \%)$.

\section{Supplementary analyses}

In a sensitivity analysis, we used a dichotomized explanatory variable (prolonged or serious conflicts at work with a supervisor and/or colleagues: yes/no) instead of four categories. To explore the differences between men and women, we stratified our analyses by sex in another sensitivity analysis. Both sensitivity analyses were carried out by rerunning the main model (model 2).

We performed all our statistical analyses in SAS version 9.2 .

\section{Results}

A total of 736 (11.4\%) participants were diagnosed with dementia during an average of 17.2 years of follow-up. The mean age at the time of dementia diagnosis was 82.4 (SD 7.1) years.

In Table 2, baseline characteristics of the study population are presented. In general, the four response groups did not differ substantially in terms of their baseline characteristics. However, participants who reported conflicts were considerably younger, had lower systolic blood pressure, were less satisfied with their private life social relations, and were better educated compared with those reporting no conflicts.

Overall, we did not find significant associations between conflicts at work and dementia in any of the models (Table 3). In model 2, the IRR for participants reporting prolonged or serious conflicts with a supervisor and colleagues was 1.53 (95\% $\mathrm{Cl} 0.77-3.03)$ compared with participants 
Table 2 Baseline characteristics of the study population $(N=6436)$

\begin{tabular}{|c|c|c|c|c|}
\hline \multirow[t]{2}{*}{ Characteristics } & \multicolumn{4}{|c|}{ Prolonged or serious conflicts at work } \\
\hline & $\begin{array}{l}\text { Never } \\
N=5883\end{array}$ & $\begin{array}{l}\text { Only with supervisor } \\
N=279\end{array}$ & $\begin{array}{l}\text { Only with col- } \\
\text { league, } N=157\end{array}$ & $\begin{array}{l}\text { With supervisor } \\
\text { and colleague, } \\
N=117\end{array}$ \\
\hline \multicolumn{5}{|l|}{ Outcome } \\
\hline Dementia cases during follow-up, $N(\%)$ & $696(11.8)$ & $18(6.5)$ & $13(8.3)$ & $9(7.7)$ \\
\hline \multicolumn{5}{|l|}{ Baseline characteristics } \\
\hline \multicolumn{5}{|l|}{ Socio-demographic factors } \\
\hline Age (years), mean (SD) & $61.8(10.9)$ & $55.1(9.4)$ & $53.9(10.2)$ & $53.2(9.7)$ \\
\hline Women, $N(\%)$ & $3395(57.7)$ & $120(43.0)$ & $92(58.6)$ & $59(50.4)$ \\
\hline Follow-up (years), mean (SD) & $17.1(5.4)$ & $19.1(4.6)$ & $19.7(3.7)$ & $19.0(4.9)$ \\
\hline \multicolumn{5}{|l|}{ Potential confounders } \\
\hline Educational attainment: $\leq 9$ years, $N(\%)$ & $2867(48.7)$ & $74(26.5)$ & $38(24.2)$ & $29(24.8)$ \\
\hline $\begin{array}{l}\text { Satisfied with private life social relations: more or } \\
\text { less/not at all, } N(\%)\end{array}$ & $1729(29.7)$ & $113(41.1)$ & $65(41.7)$ & $57(48.7)$ \\
\hline Have a confidant: no, $N(\%)$ & $416(7.1)$ & $19(6.8)$ & $11(7.0)$ & $10(8.6)$ \\
\hline Psychiatric disorders: yes, $N(\%)$ & $361(6.1)$ & $26(9.3)$ & $19(12.1)$ & $8(6.8)$ \\
\hline \multicolumn{5}{|l|}{ Potential mediators } \\
\hline Diabetes/CVD: yes, $N(\%)$ & $391(6.7)$ & $15(5.4)$ & $7(4.5)$ & Few obs. ${ }^{\mathrm{a}}$ \\
\hline Smoking: current smoker, $N(\%)$ & $2857(48.6)$ & $137(49.1)$ & $63(40.1)$ & $63(53.9)$ \\
\hline $\begin{array}{l}\text { Physical activity during leisure time: almost } \\
\text { sedentary life, } N(\%)\end{array}$ & $658(11.2)$ & $29(10.4)$ & $15(9.6)$ & $15(12.9)$ \\
\hline Alcohol (average unit per week), mean (SD) & $9.2(12.0)$ & $13.0(14.2)$ & $9.9(11.3)$ & $11.2(11.3)$ \\
\hline BMI $\left(\mathrm{kg} / \mathrm{m}^{2}\right)$, mean $(\mathrm{SD})$ & $26.0(4.3)$ & $25.7(4.3)$ & $25.5(3.9)$ & $25.5(4.7)$ \\
\hline Systolic blood pressure, mean (SD) & $142(21)$ & $135(20)$ & $129(19)$ & $130(20)$ \\
\hline Takes sleeping pills: yes, $N(\%)$ & $478(8.2)$ & $15(5.4)$ & $9(5.7)$ & $6(5.1)$ \\
\hline
\end{tabular}

${ }^{\mathrm{a}}$ Few obs.- due to a restriction from the Statistics Denmark, we were not allowed to present any information which contains a frequency $\leq 3$

Table 3 Incidence rate ratios (IRR) with 95\% confidence interval (CI) for incident dementia in participants according to experiencing prolonged or serious conflicts at work

\begin{tabular}{|c|c|c|c|c|c|}
\hline & \multirow{2}{*}{$\begin{array}{l}\text { No. of dementia cases } \\
N=736 / 6,436(11.4 \%)\end{array}$} & \multirow{2}{*}{$\begin{array}{l}\text { Univariate analysis } \\
\text { IRR }(95 \% \mathrm{Cl})\end{array}$} & \multicolumn{3}{|c|}{ Multivariable analyses } \\
\hline & & & $\begin{array}{l}\text { Model } 1 \\
\text { IRR }(95 \% \mathrm{Cl})\end{array}$ & $\begin{array}{l}\text { Model } 2 \\
\text { IRR }(95 \% \mathrm{Cl})\end{array}$ & $\begin{array}{l}\text { Model } 3 \\
\text { IRR }(95 \% \mathrm{Cl})\end{array}$ \\
\hline Never had conflict & $696 / 5883(11.8 \%)$ & 1 & 1 & 1 & 1 \\
\hline Only with supervisor & $18 / 279(6.5 \%)$ & $0.53(0.33-0.84)$ & $0.87(0.54-1.41)$ & $0.90(0.56-1.46)$ & $0.84(0.51-1.38)$ \\
\hline Only with colleague & $13 / 157(8.3 \%)$ & $0.71(0.42-1.21)$ & $0.98(0.54-1.78)$ & $1.06(0.58-1.94)$ & $1.12(0.61-2.06)$ \\
\hline $\begin{array}{l}\text { Conflicts with supervisor } \\
\text { and colleague }\end{array}$ & $9 / 117(7.7 \%)$ & $0.74(0.39-1.41)$ & $1.45(0.73-2.88)$ & $1.53(0.77-3.03)$ & $1.55(0.78-3.10)$ \\
\hline
\end{tabular}

Model 1: adjusted for current age, sex, time since baseline assessment and calendar year

Model 2: model $1+$ educational attainment, private life social relations, psychiatric disorders

Model 3: model 2+ comorbidities (CVD and diabetes), and lifestyle/CVD-risk factors (smoking, physical activity during leisure time, alcohol, BMI, blood pressure, and use of sleeping pills)

reporting no such conflicts. In model 3 , the estimate remained essentially the same when adjusting for potential mediators. The IRR for participants who had prolonged or serious conflicts either with a supervisor or with colleagues did not differ from unity, and the IRRs were $0.90(95 \% \mathrm{Cl}$
$0.56-1.46)$ and $1.06(95 \% \mathrm{Cl} 0.58-1.94)$, respectively, in model 2.

When we treated the explanatory variable as dichotomous in a sensitivity analysis, the association between experiencing conflicts at work and incident dementia became 
negligible with an IRR of 1.05 (95\% $\mathrm{Cl} 0.75-1.48)$ (not shown in tables).

Results from the second sensitivity analysis showed that the estimated differences (IRRs) were larger in men than in women (Table 4). The adjusted IRR for men who reported having had prolonged or serious conflicts both with a supervisor and colleagues was $2.14(95 \% \mathrm{Cl} 0.97-4.71)$, but for women, the IRR was 0.98 (95\% Cl 0.29-3.32). Yet, the 95\% CIs are broad and overlapping.

\section{Discussion}

\section{Main findings}

In this prospective population-based study of 6,436 Danish middle-aged men and women, we found no overall association between experiencing prolonged or serious conflicts at work and incident dementia in old age. The IRR for the association between conflicts at work and dementia was considerably larger in men than in women. However, these results are based on few cases and with overlapping CI.

\section{Comparison with previous studies}

To the best of our knowledge, no previous studies have investigated the association between conflicts at work and the risk of dementia. In most cases, clinical dementia is preceded by a decline in cognitive function, and although a decline in cognitive function does not always lead to a dementia diagnosis (Richard and Brayne 2014); we also include results from studies of cognitive functioning in the following discussion.

Our findings are in contrast to results from two previous studies that reported an adverse effect of negative aspects of social relations on cognitive function (Liao et al. 2014; Xu et al. 2016). Yet, another study showed no effect (Seeman et al. 2001), and another one reported better cognitive function among participants reporting higher social interactions

Table 4 Incidence rate ratios (IRR) with 95\% confidence interval (CI) for incident dementia according to sex

\begin{tabular}{lll}
\hline Explanatory variable & $\begin{array}{l}\text { Men }(N=2770), \text { IRR, } \\
(95 \% \mathrm{Cl})\end{array}$ & $\begin{array}{l}\text { Women } \\
(N=3666), \mathrm{IRR}, \\
(95 \% \mathrm{Cl})\end{array}$ \\
\hline Never had conflict & 1 & 1 \\
Only with supervisor & $1.06(0.60-1.90)$ & $0.66(0.27-1.60)$ \\
Only with colleague & $1.25(0.55-2.82)$ & $0.91(0.37-2.23)$ \\
Conflicts with both & $2.14(0.97-4.71)$ & $0.98(0.29-3.32)$ \\
\hline
\end{tabular}

Adjusted for current age, time since baseline assessment, calendar year, educational attainment, private life social relations and psychiatric disorders
(Hughes et al. 2008). Similar to our study, some of these past studies estimated negative social relations in midlife (Liao et al. 2014; Seeman et al. 2011). Nevertheless, the contradictions between our findings and findings from past studies suggest a differential role of social relations at work versus social relations in private life on cognitive function. Social relations in private life could be more important to people, and the impact may often be more prolonged, whereas people are likely to leave their job if they experience major conflicts at work.

Our findings raise the question whether there is a sex difference in the association between conflicts at work and dementia. Having conflicts with a supervisor and colleagues appear to be associated with a higher risk of dementia among men, although, none of the estimates were statistically significant and the results were based on few cases. Only a few studies stratified their analyses by sex (Liao et al. 2014; Seeman et al. 2001). However, these studies did not reveal any difference between men and women regarding the association between negative social relations and cognitive function. Because of gender segregation (both horizontal and vertical) at the Danish labor market in the 1980s and 1990s (Bloksgaard 2011), the psychosocial working environment may have differed between male- and female-dominated jobs. Such differences may partly explain the difference between men and women regarding the association between conflicts at work and dementia. However, we cannot support this hypothesis with empirical data, as we do not have information about the participants' working environment.

We hypothesized that as a severe stressor, conflicts at work might be linked to the risk of dementia in old age through various potential mechanisms. For example, conflicts could cause prolonged stress that leads to brain atrophy and $\mathrm{A} \beta$ deposition in the brain, which are considered hallmarks of Alzheimer's disease. Prolonged stress also influences cardiovascular health, mental health and health-related behaviors, which could eventually lead to dementia. However, our data did not support our hypothesis. There may be several reasons for the negative results, including the possibility that (1) the follow-up time was too long resulting in a dilution of the effect, (2) we had too few cases, (3) conflicts were only assessed at one point in time, (4) the applied questions assessing conflicts at work were insufficient to assess actual conflicts, or (5) that our hypothesis was not valid.

\section{Strengths and limitations of the study}

The main strength of our study is the long-term follow-up and the exclusion of the first 5 years of follow-up after the baseline assessment, which was done to reduce the risk of reverse causation, although reverse causation might still be a concern (Sperling et al. 2011). Nevertheless, with the long follow-up time, the association is likely to be diluted. This 
might be difficult to avoid when investigating long-term effects of midlife exposures on an outcome occurring primarily in old age, such as dementia. An additional strength of the current study is the adjustment for a wide range of covariates including various indicators of private life social relations, e.g., satisfaction with private life social relations and having a confidant or not. Furthermore, there was a negligible loss to follow-up due to emigration.

One of the main limitations of the present study is the low prevalence of participants who reported prolonged or serious conflicts at work (8.5\%). The prevalence was somewhat lower than observed in a recent survey in Denmark, in which conflicts at work were operationalized as "experiencing any quarrels or conflicts at work within the past 12 months" (The National Research Center for the Working Environment 2016). Conflicts at work have been investigated within the past decades, within the areas of organizational management and occupational medicine. Some scales for assessing conflicts at work were developed in the 1980s and 1990s, including the Interpersonal Conflict at Work Scale, the Organizational Constraints Scale, and the Quantitative Workload Inventory (Spector and Jex 1998). In our data, conflicts were assessed by two questions, and our measures might not include all the variations that the more comprehensive scales capture. Future studies should investigate the association between conflicts at work and dementia using a validated scale. As our measures of conflicts at work did not address the number, duration, severity, and timing of conflicts at work, we are likely to miss information that is important for the hypothesized association between these conflicts and dementia risk. Also, our measures cannot differentiate between the duration and severity of conflicts, as it combines "prolonged" and "serious" conflicts as one entity although the two could have different effects. Another limitation related to our measures of conflicts is that they were assessed at only one point in time. This could have led to exposure misclassification, which may have diluted the observed association between conflicts and dementia.

Furthermore, self-reported information on conflicts at work and private life social relations can be influenced by individual characteristics. For instance, people who score high on the personality trait neuroticism may report more conflicts and negative social relations. According to a recent review, neuroticism has been shown to increase the risk of dementia, while conscientiousness protects against dementia (Low et al. 2013). Moreover, other studies have suggested that neuroticism increases the risk of interpersonal conflicts at work (Appelberg et al. 1991) and decreases the number of confidants (Kendler et al. 2003). Therefore, our results could be confounded by unmeasured personality factors. Lifestylerelated factors, e.g., smoking, physical activity during leisure time, and alcohol consumption, can reflect people's behavior and thereby also certain personality traits. However, we cannot confirm this hypothesis with our data. Adjustment for lifestyle-related factors in our analysis, however, did not change the results substantially.

Among other unmeasured confounders, work-related factors (job control and job complexity) and cognitive ability at baseline may have influenced our results. Low job control and low job complexity in midlife are associated with lower cognitive function and a higher risk of dementia in old age (Then et al. 2014). We adjusted for educational attainment in our analyses, as educational attainment influences what type of occupation a person will have. Furthermore, a recent study suggested occupational complexity strongly mediates the cognitive gain associated with higher levels of education (Fujishiro et al. 2017). Also, educational attainment has been shown to be strongly correlated with cognitive ability in both young adulthood and later life (Mortensen et al. 2014). Yet, adjustment for education did not considerably change the results in the present study. Therefore, it is unlikely that lack of adjustment for job complexity and baseline cognitive ability has substantially influenced our results. Furthermore, we did not have full information on the number of years of employment before baseline, which could be a confounder and may have affected our results.

We adjusted for aspects of social relations in private life in our analyses, but not for other aspects of social relations at work than prolonged or serious conflicts. Both low social support at work (Andel et al. 2012) and a lack of contact with colleagues during working hours (Ishtiak-Ahmed et al. 2017) have been shown to be associated with higher risk of dementia. The buffering effect of social support on stressful life events in relation to health outcomes is well documented in the literature (Umberson et al. 2010). Also, individuals with social support at work may react differently to prolonged or serious conflicts at work compared with individuals without social support.

A validation study reported that the positive predictive value of the registered dementia diagnoses in the Danish national hospital registers was 86\% (Phung et al. 2007). However, the hospital registers only capture about two-thirds of all cases in Denmark (Phung et al. 2010). This underreporting could have affected our results by diluting the association between conflicts and dementia in the present study. It is unlikely that missing information has influenced our results as only $1.1 \%$ had at least one variable with missing information among the covariates included for adjustments in the main analyses.

Another concern is that $10 \%$ of the 10,135 participants in the third survey of CCHS did not respond to the questions on conflicts at work. Non-responders have increased mortality and morbidity in most epidemiological studies (Rothman et al. 2008). If they had had more conflicts at work compared to responders, it can blunt our results. The percentages of dementia among the excluded and included participants were 
$16 \%$ and $11 \%$ respectively, and the incidence rates were 156 and 119 per 10,000 person-years, respectively. Furthermore, among the 837 participants (mean age: 70 years) who were excluded due to death within the first 5 years since baseline assessment, $4.2 \%$ of them reported experiencing conflicts at work compared to $8.5 \%$ of the included participants, indicating that the participants' status of reporting conflicts may not have influenced these deaths. Thus, the exclusion based on mortality within five years from baseline are unlikely to affect our results.

\section{Conclusions}

This is the first prospective study investigating the impact of conflicts at work on the risk of dementia in old age. Our data did not support an association between experiencing prolonged or serious conflicts at work and the risk of dementia. However, our results were based on a few cases. Because of the large difference between the point estimates for men and women in our sensitivity analyses, we cannot draw firm conclusions on sex difference, but it may be relevant for future studies to explore sex differences in the association between conflicts at work and incident dementia.

Acknowledgements The study was part of a $\mathrm{PhD}$ project funded by The Danish Working Environment Research Fund (Grant number 10-2015-03 20150017498). The funder had no role in the writing of the paper, the analysis of data, the interpretation of the results and the conclusion. The funder had no role in the decision to submit the manuscript for publication.

\section{Compliance with ethical standards}

Conflict of interest The authors declare that they have no conflict of interest.

Ethical approval All procedures performed in studies involving human participants were in accordance with the ethical standards of the institutional and/or national research committee and with the 1964 Helsinki declaration and its later amendments or comparable ethical standards.

Informed consent Informed consent was obtained from all individual participants included in the study.

Availability of data and material The data used in this study are from Statistics Denmark. However, they are not publicly available. Special permission is required to use the data for research in compliance with the Danish Data Privacy Act.

Open Access This article is distributed under the terms of the Creative Commons Attribution 4.0 International License (http://creativeco mmons.org/licenses/by/4.0/), which permits unrestricted use, distribution, and reproduction in any medium, provided you give appropriate credit to the original author(s) and the source, provide a link to the Creative Commons license, and indicate if changes were made.

\section{References}

Aguib Y, Al Suwaidi J (2015) The Copenhagen City Heart Study (Østerbroundersøgelsen). Glob Cardiol Sci Pract 2015(3):33

Andel R et al (2012) Work-related stress may increase the risk of vascular dementia. J Am Geriatr Soc 60(1):60-67

Andersen TF, Madsen M, Jorgensen J, Mellemkjoer L, Olsen JH (1999) The Danish National Hospital Register. A valuable source of data for modern health sciences. Dan Med Bull 46(3):263-268

Appelberg K, Romanov K, Honkasalo ML, Koskenvuo M (1991) Interpersonal conflicts at work and psychosocial characteristics of employees. Soc Sci Med 32(9):1051-1056

Appelberg K, Romanov K, Heikkila K, Honkasalo ML, Koskenvuo M (1996) Interpersonal conflict as a predictor of work disability: a follow-up study of 15,348 Finnish employees. J Psychosom Res 40(2):157-167

Bloksgaard L (2011) Masculinities, femininities and work-the horizontal gender segregation in the Danish labour market. Nordic J Work Life Stud 1(2):5-21

Bolger N, DeLongis A, Kessler RC, Schilling EA (1989) Effects of daily stress on negative mood. J Pers Soc Psychol 57(5):808-818

Carsten KWDD, Dirk van D, Maria TMD (2004) Conflict at work and individual well-being. Int J Conflict Manag 15(1):6-26. https://doi.org/10.1108/eb022905

Cohen S (2004) Social relationships and health. Am Psychol 59(8):676-684

De Raeve L, Jansen NW, van den Brandt PA, Vasse R, Kant IJ (2009) Interpersonal conflicts at work as a predictor of self-reported health outcomes and occupational mobility. Occup Environ Med 66(1):16-22

Dong H, Csernansky JG (2009) Effects of stress and stress hormones on amyloid-beta protein and plaque deposition. JAD 18(2):459-469

Due P, Holstein B, Lund R, Modvig J, Avlund K (1999) Social relations: network, support and relational strain. Soc Sci Med 48(5):661-673

Fortunato VJ, Harsh J (2006) Stress and sleep quality: The moderating role of negative affectivity. Personal Individ Differ 41(5):825-836

Frone MR (2000) Interpersonal conflict at work and psychological outcomes: testing a model among young workers. J Occup Health Psychol 5(2):246-255

Fujishiro K, MacDonald LA, Crowe M, McClure LA, Howard VJ, Wadley VG (2017) The Role of Occupation in Explaining Cognitive Functioning in Later Life: Education and Occupational Complexity in a U.S. National Sample of Black and White Men and Women. J Gerontol. https://doi.org/10.1093/geronb/gbx112

Gottesman RF, Schneider AC, Zhou Y et al (2017) Association between midlife vascular risk factors and estimated brain amyloid deposition. JAMA 317(14):1443-1450

Hagerty BM, Williams RA (1999) The effects of sense of belonging, social support, conflict, and loneliness on depression. Nurs Res 48(4):215-219

Helweg-Larsen K (2011) The Danish Register of causes of death. Scand J Public Health 39(7 Suppl):26-29

Hughes TF, Andel R, Small BJ, Borenstein AR, Mortimer JA (2008) The association between social resources and cognitive change in older adults: evidence from the Charlotte County Healthy Aging Study. J Gerontol B Psychol Sci Soc Sci 63(4):P241-P244

Ishtiak-Ahmed K et al (2017) Social relations at work and incident dementia: 29-years' follow-up of the Copenhagen male study. J Occup Environ Med 60(1):12-18

Johansson L et al (2010) Midlife psychological stress and risk of dementia: a 35-year longitudinal population study. pp 1460-2156 (Electronic) 
Johansson L et al (2012) Midlife psychological distress associated with late-life brain atrophy and white matter lesions: a 32-year population study of women. pp 1534-7796 (Electronic)

Kendler KS, Gardner CO, Prescott CA (2003) Personality and the experience of environmental adversity. Psychol Med 33(7):1193-1202

Kivipelto M et al (2001) Midlife vascular risk factors and Alzheimer's disease in later life: longitudinal, population based study. BMJ pp 0959-8138 (Print)

Kuiper JS et al (2015) Social relationships and risk of dementia: a systematic review and meta-analysis of longitudinal cohort studies. Ageing Res Rev 22:39-57

Kuiper JS et al (2016) Social relationships and cognitive decline: a systematic review and meta-analysis of longitudinal cohort studies. Int J Epidemiol 45(4):1169-1206

Liao J et al (2014) Negative Aspects of Close Relationships as Risk Factors for Cognitive Aging. Am J Epidemiol 180(11):1118-1125

Livingston $\mathrm{G}$ et al (2017) Dementia prevention, intervention, and care. The Lancet. https://doi.org/10.1016/S0140-6736(17)31363-6

Low LF, Harrison F, Lackersteen SM (2013) Does personality affect risk for dementia? A systematic review and meta-analysis. Am J Geriatr Psychiatry 21(8):713-728. https://doi.org/10.1016/j. jagp.2012.08.004

Malgorzata M, Elke S, Eusebio RG (2009) European agency for safety and health at work-European risk observatory report 2009

Meier LL, Semmer NK, Gross S (2014) The effect of conflict at work on well-being: Depressive symptoms as a vulnerability factor. Work Stress 28(1):31-48

Mortensen EL et al (2014) The relationship between cognitive ability and demographic factors in late midlife. J Aging Health 26(1):37-53

Munk-Jorgensen P, Mortensen PB (1997) The Danish Psychiatric Central Register. Dan Med Bull 44(1):82-84

Phung TK, Andersen BB, Hogh P, Kessing LV, Mortensen PB, Waldemar G (2007) Validity of dementia diagnoses in the Danish hospital registers. Dement Geriatr Cogn Disord 24(3):220-228

Phung TKT, Waltoft BL, Kessing LV, Mortensen PB, Waldemar G (2010) Time trend in diagnosing dementia in secondary care. Dement Geriatr Cogn Disord 29(2):146-153

Richard E, Brayne C (2014) Mild cognitive impairment-not always what it seems. Nat Rev Neurol 10:130

Rod NH, Gronbaek M, Schnohr P, Prescott E, Kristensen TS (2009) Perceived stress as a risk factor for changes in health behaviour and cardiac risk profile: a longitudinal study. J Intern Med 266(5):467-475

Romanov K, Appelberg K, Honkasalo ML, Koskenvuo M (1996) Recent interpersonal conflict at work and psychiatric morbidity: a prospective study of 15,530 employees aged 24-64. J Psychosom Res 40(2):169-176
Rothman K, Greenland S, Lash T (2008) Modern epidemiology. Lippincott Williams \& Wilkins, Philadelphia

Seeman TE, Lusignolo TM, Albert M, Berkman L (2001) Social relationships, social support, and patterns of cognitive aging in healthy, high-functioning older adults: MacArthur studies of successful aging. Health Psychol 20(4):243-255

Seeman TE, Miller-Martinez DM, Stein Merkin S, Lachman ME, Tun PA, Karlamangla AS (2011) Histories of social engagement and adult cognition: midlife in the U.S. study. J Gerontol Ser B Psychol Sci Soc Sci 66B(Suppl 1):i141-i152

Sherman SM, Cheng YP, Fingerman KL, Schnyer DM (2016) Social support, stress and the aging brain. Soc Cogn Affect Neurosci 11(7):1050-1058

Spector PE, Bruk-Lee V (2008 2008) Conflict, health, and well-being. In: The psychology of conflict and conflict management in organizations. The organizational frontiers series. Taylor \& Francis Group/Lawrence Erlbaum Associates, New York, pp 267-288

Spector PE, Jex SM (1998) Development of four self-report measures of job stressors and strain: Interpersonal Conflict at Work Scale, Organizational Constraints Scale, Quantitative Workload Inventory, and Physical Symptoms Inventory. J Occup Health Psychol pp 1076-8998 (Print)

Sperling RA et al (2011) Toward defining the preclinical stages of Alzheimer's disease: recommendations from the National Institute on Aging-Alzheimer's Association workgroups on diagnostic guidelines for Alzheimer's disease. Alzheimers Dement 7(3):280-292

Stein J, Schettler T, Rohrer B, Valenti M (2008) Environmental Threats to Healthy Aging: With a Closer Look at Alzheimer's \& Parkinson's Diseases (Chap. 7 Environmental Factors in the Development of Dementia Focus on Alzheimer's Disease and Cognitive Decline). Boston, USA, p 97-143

Steptoe A, Kivimaki M (2012) Stress and cardiovascular disease. Nat Rev Cardiol pp 1759-5010 (Electronic)

The National Research Center for the Working Environment (2016) Danish Work Environment 2014. National Research Center for the Working Environment, Copenhagen

Then FS et al (2014) Systematic review of the effect of the psychosocial working environment on cognition and dementia. Occup Environ Med 71(5):358-365

Umberson D, Crosnoe R, Reczek C (2010) Social Relationships and Health Behavior Across Life Course. Annu Rev Sociol 36:139_ 157. https://doi.org/10.1146/annurev-soc-070308-120011

Xu M, Thomas PA, Umberson D (2016) Marital Quality and Cognitive Limitations in Late Life. J Gerontol B Psychol Sci Soc Sci 71(1):165-176 